\title{
ASIMETRÍAS DE GÉNERO EN LA LEY GENERAL DE EDUCACIÓN. TRANSFORMACIÓN CULTURAL Y FORMACIÓN DEL PROFESORADO EN ESPAÑA
}

\author{
Teresa González Pérez \\ teregonz@ull.edu.es \\ Universidad de La Laguna - España
}

Recibido: 11-01-2016

Aceptado: 05-05-2016

\section{Resumen}

La formación del profesorado constituye un soporte básico del sistema educativo. Nuestro objetivo consiste en estudiar el modelo de formación del profesorado de Educación General Básica que ha existido en España desde la configuración de este nivel educativo con la Ley General de Educación (1970) hasta la promulgación de la Ley de Ordenación General del Sistema Educativo (1990). En dicho análisis se consideran algunas cuestiones básicas de la formación así como la variable de género. Hemos empleado la metodología de análisis histórico educativo, siguiendo el procedimiento habitual de este diseño metodológico. El estudio histórico educativo nos permitió conocer la política educativa para la formación del profesorado y vislumbrar las diferencias de género en el contexto social y político del tardofranquismo en tránsito a la monarquía constitucional. Con estas aportaciones contribuimos a la reflexión sobre los programas de formación docente.

Palabras Clave: Política educativa, formación de profesorado, desigualdades, roles de género.

\begin{abstract}
Teacher training is a basic support of the educational system. Our goal is to study the model of teacher training for basic general education that has existed in Spain since the configuration of this level with the General Education Law (1970) until the enactment of the Law on General Education System (1990). In the analysis, some basic questions of training and the gender variable are considered. We used the methodology of educational historical analysis, following the usual procedure of this methodological design. The educational historical study allowed us to meet the educational policy for teacher training and glimpse gender differences in the social and political context of later Francoism in transition to constitutional monarchy. With these contributions, we provide elements for the reflection on teacher training programs.
\end{abstract}

Keywords: Educational policy, teacher education, inequalities, gender roles. 


\section{Introducción}

Las políticas educativas generan transformaciones cuyo grado de intensidad depende de los distintos gobiernos y de las ideologías dominantes. Cambios educativos de distinta naturaleza que contribuyen a la transformación de la sociedad con una "dimensión propedéutica" (Torres, 2001: 171). Con gobiernos autoritarios las leyes vienen impuestas de facto, impidiendo la intervención y debates en cualquier sentido. En España, la Ley General de Educación (1970), aprobada en el ocaso de la dictadura, intentaba resolver los grandes problemas de atraso de la sociedad española construyendo un modelo educativo amplio, que extendiera la escolarización a todos los sectores poblacionales además de la consiguiente reforma en todos los niveles educativos. La Ley General de Educación (LGE) reguló el sistema educativo conjugando tradiciones con la modernidad a pesar de mantener activos los valores ideológicos del régimen dictatorial (Rodríguez, 2008:102). Se planteaba, por primera vez, eliminar la pedagogía de la exclusión y alfabetizar a toda la población. Un avance innovador importante que pretendía la transformación cultural, pero tenía el reto de modernizar sus estructuras educativas aún en el seno de la dictadura. Sin duda, una ley precursora de modelos democráticos de enseñanza que tuvo que sortear diversos obstáculos, desde la financiación al profesorado (Blat, 1977:21). Entre los objetivos de la ley figuraban los principios de igualdad. La igualdad social y de género como medio de distribución igualitaria, considerando la educación medio de movilidad y promoción. De todos modos, aunque el progreso educativo no sintonizaba con el orden político, la ley modernizó la educación española y reestructuró el sistema educativo en todos sus niveles. La mayor aportación fue pretender la generalización de la educación básica a toda la población activando la igualdad de oportunidades. Aunque es cierto que la dualidad de titulaciones discriminaba al alumnado según obtuviera al finalizar los estudios el graduado escolar o el certificado de escolaridad. Con la aplicación de dicha ley la escolaridad pública se extendió y se crearon más puestos escolares; así se beneficiaron los niños y niñas de las áreas rurales al tiempo que se incrementó la plantilla docente. Las inscripciones escolares y la apertura de nuevos colegios públicos marchó a un ritmo creciente, en cambio, la matrícula en los colegios privados resultó más lenta y, en algunos casos, se estancó. No fue tarea fácil llevar la educación a todos y a todas para mejorar el nivel cultural de la población española.

La reforma afectó a la formación del profesorado. Una reforma que no pasó desapercibida porque las medidas legislativas modificaron los esquemas conocidos hasta aquellos momentos. Las alteraciones burocráticas y formales, introduciendo nuevos rótulos, sustituyendo terminologías rutinarias por otras novedosas, forzó cambios metodológicos. Con la Ley General de Educación se instituyeron las Escuelas Universitarias de Formación del Profesorado de Enseñanza General Básica para reemplazar a las Escuelas de Magisterio. Un avance importante y un significativo cambio cualitativo que situaba la formación del magisterio a nivel universitario (con la expedición del título de Diplomados), recuperando la titulación universitaria perdida tras la guerra civil. Con la promulgación del Plan de Estudios de 1971 la formación inicial, del colectivo 
denominado Profesorado de Enseñanza General Básica, otrora maestros y maestras, se diversificó en especialidades a la vez que se unificó el currículum entre sexos (González, 2010).

El presente estudio se inscribe en el marco de un trabajo de investigación más amplio, referido a la formación docente ${ }^{1}$. La hipótesis de este trabajo sostiene que la formación de los estudiantes de magisterio estuvo marcada por la renovación educativa y los roles de género. En su itinerario, además de instruir en los aspectos pedagógico-científicos, no desatendió las cuestiones relativas a la masculinidad y feminidad. Pero esa atención, lejos de ser explícita en las prescripciones, operó en el plano de las enseñanzas implícitas que, aunque ocultas, apuntaron a modelar a un hombre ejemplar y una mujer ejemplar capaz de representar a los maestros y a las maestras respectivamente. Nuestro objetivo es conocer la política educativa española, para la formación del profesorado y de qué manera repercutió en el rol de los docentes. Para la investigación hemos empleado la metodología de análisis histórico-educativa (siguiendo las fases de estudio correspondientes: heurística, hermenéutica y exposición/síntesis para el debate científico) apoyada en fuentes documentales y bibliográficas, examinamos textos legislativos y revisamos bibliografía.

\section{La extensión de la educación obligatoria y los nuevos perfiles docentes}

La aplicación de la LGE representó un avance en la etapa final de la dictadura, a la vez que preludiaba cambios políticos sin posibilidad de retorno. El despegue económico, las mejoras en la sociedad y desarrollo de la clase media flexible al progreso y abierta a nuevas ideas propiciaban la evolución. Se fraguaba una mentalidad que operó a favor de la sociedad democrática. La normativa ofreció una nueva perspectiva a la profesión docente en correspondencia con las necesidades de progreso de la sociedad española de entonces. Al fijar las etapas educativas también se definieron los perfiles marcados en las profesiones docentes, profesorado de Enseñanza General Básica (antes denominados maestras y maestros) en el sistema obligatorio y profesorado de bachillerato o enseñanza secundaria, con orientaciones distintas en correspondencia con sus diversos orígenes. Se impulsaba el ascenso de las clases subalternas y la mayor demanda de conocimientos profesionales, en tanto que para la etapa secundaria garantizaba un aumento de conocimientos profesionales especializados, que preparaba para el ejercicio de puestos de responsabilidad, conformado por las élites que preparaba el sistema de enseñanza. De manera que el magisterio se infravaloraba y presentaba escasas expectativas de movilidad social. En torno a un $70 \%$ del magisterio procedía de los estratos sociales medio-bajos y accedían a estos estudios como estrategia de mejora en la estructura social. La construcción de esta creencia estaba

\footnotetext{
1 Este trabajo forma parte del proyecto de investigación $(\mathrm{I}+\mathrm{D}+\mathrm{i})$ del Ministerio de Economía y Competitividad. Referencia EDU2011-28944: La Ley General de Educación y el modelo de formación de maestros y maestras en España.
} 
relacionada con los bajos salarios que recibían por su ejercicio profesional y su origen social (Alonso, 1991: 356).

La universalización y ampliación de la enseñanza provocó un cambio estructural en el sistema educativo y en la formación del profesorado. En 1971 el Plan de estudios con carácter experimental fue refrendado de forma oficial en la Orden Ministerial 1411/77 (BOE de 13 de junio de 1977). Los profesores de Enseñanza General Básica debían estar capacitados para impartir una enseñanza globalizada en la primera etapa de la Enseñanza General Básica (EGB) y en un Área de moderada especialización (Ciencias, Ciencias Humanas y Lengua extranjera) en la segunda etapa de la EGB. La extensión de la escolarización supuso una constante transformación del currículo de la enseñanza primaria, hecho que exigió una mayor preparación y formación del magisterio. Es decir, la formación docente para un periodo estándar y de carácter masivo de la población escolar entre los 6 y 14 años ( $1^{\circ}$ y $2^{\circ}$ etapa). Con la extensión de la escolarización, que abarcaba un tramo sustraído del bachillerato (11-14 años), se intentaba resolver o mejor dicho paliar desigualdades, un proceso que no dejaba de ser una manera de popularizar el nivel. Además la segunda etapa era obligatoria y el alumnado, heterogéneo y dispar, ya no constituía una minoría como sucedía en la secundaria en la década anterior (Puelles, 2011: 22-23). El estudiantado se diversificó, accediendo de distintos estratos sociales pues se incluían a todos en la escuela (Esteve, 2003: 53; Viñao, 2011: 466). Sin embargo, el profesorado se resintió y se tropezó con sus mentalidades, cultura e identidades. Afectó tanto en el colectivo docente que impartía estudios de bachillerato como en el que se dedicaba a la enseñanza primaria (Puelles, 2011: 26).

La modificación del rol docente y de la re-construcción de la identidad profesional precisaba una amplia dedicación para prepararse en teoría y desarrollo curricular, también para desarrollar metodologías didácticas (González-Gil y Martín Pastor, 2014). Los maestros y maestras necesitaban tiempo para el aprendizaje, de la misma forma que el profesorado de las Escuelas Universitarias encargados de la formación inicial. El colectivo docente se enfrentaba a nuevos retos y retóricas, lo cual acarreaba dificultades ante un horizonte educativo que en aquél contexto, se hacía complejo. Un indudable desafío para el profesorado que vio condicionado el grado de atención a prestar a su ejercicio docente. En un contexto de incertidumbre, se confiaba en movilizar la capacidad para aprender del magisterio con el objeto de regenerar la educación y movilizar la capacidad interna de cambio en las escuelas. De este modo, las estrategias burocráticas y verticales del cambio limitaban el protagonismo a los agentes educativos, porque no se sentían involucrados ni identificados con la reforma y tampoco con la imagen social. La UNESCO en 1975 hizo una serie de recomendaciones formativas para el profesorado ${ }^{2}$. Hecho que reflejaba una preocupación académica con proyección internacional. Unas propuestas fueron avanzando y modernizando las estructuras formativas hasta llegar, progresivamente, al

\footnotetext{
${ }^{2}$ UNESCO. Recomendación sobre la evolución del papel del personal docente y consecuencias de esa evolución en la formación profesional previa y en servicio, XXXV Conferencia Internacional de la Educación, Ginebra, 1975.
} 
fenómeno globalizador de carácter mundial que planteaba un nuevo orden educativo que difumina los sistemas educativos nacionales (González, 2013).

La transformación de toda la enseñanza en España, con frecuentes cambios en los equipos políticos y en sus programas de actuación, requería un tiempo de adaptación. Los equipos que trabajaban en el ministerio introdujeron modificaciones, en ocasiones, incoherentes. La transición a la democracia fue una etapa convulsa, donde se produjeron cambios importantes en la política y la población española. La sociedad evolucionaba después de su encorsetamiento, pero alejarse de la sociedad autoritaria tenía sus rémoras. El sistema se fue flexibilizando y la sociedad española entró en un proceso de transformación. Se inició la etapa de la transición que condujo a la restauración democrática. En este contexto se produjo la renovación pedagógica y el progreso hacia la democracia escolar y la pluralidad de alternativas. Las experiencias educativas de la sociedad predemocrática resultaron cruciales para variar el rumbo de la escuela. La educación pretendía dar respuesta a las necesidades sociales, a los discursos que enfatizaban la diferencia y a las demandas frente al centralismo político. Dentro de este contexto modernizador se pretendía recuperar las tradiciones pedagógicas del primer tercio de siglo que abanderaron la educación española. El currículum se modificó y diversificó, trazando una formación académica más equilibrada entre las disciplinas. A partir de la transición se produjo la remodelación de las enseñanzas y se incorporó la formación en la especialidad de Preescolar y la especialidad de Educación Especial (Diego, 2013: 67).

Otro aspecto significativo fue el acceso de los sectores populares a la educación superior, como se indicó anteriormente. Se produjo un trasvase de la educación de élites a la educación de masas, con lo cual España se aproximaba a los países del entorno europeo. No obstante, las inversiones en el sistema educativo aún se hallaban distantes de los países más avanzados. Los recursos económicos invertidos seguían siendo insuficientes para cubrir adecuadamente los gastos que requería la expansión educativa. Un desfase que se reflejó en las múltiples deficiencias, tales como infra dotación escolar, déficit docente, precarias instalaciones, etc. Las prácticas pedagógicas también evolucionaron, si bien buena parte de los colectivos docentes se movían por las rutinas e inercias de antaño. Hubo lentitud en modernizar las metodologías didácticas y amplios sectores del profesorado, aferrados a los viejos métodos y creencias, permanecieron impermeables a los cambios.

La sociedad española protagonizó un notable cambio, no solo la transición a la democracia sino también, posteriormente, con el desarrollo del estado de las autonomías y la incorporación a la Unión Europea. Desde la decadencia de la dictadura franquista, los años de la transición remataron con el "engranaje" y consenso realizado por los gobiernos democráticos (Puelles, 2004:70). También desarrollaron un destacado papel los estudiantes que con sus luchas antifranquistas defendieron la democracia y posibilitaron cambios en las aulas (Hernández, 2008:83). La responsabilidad de los poderes públicos en la realización del derecho a la educación, para lograr esa escuela de todos, fue un hecho que significó el progreso de las dos últimas décadas del siglo XX. España, como otros países de su entorno, ha construido su sistema educativo desde la actuación de los poderes públicos. 
Hasta los primeros años de la restauración democrática no se alcanzó la escolarización total de la enseñanza obligatoria, descendió la ratio maestro-alumno, se reforzó la enseñanza pública y se innovó en los centros. El periodo de la transición marcó el antes y el después, con acuerdos y consensos que hicieron factible la resolución de los diversos problemas que afectaban a la educación. Los pactos políticos y sociales realizados en 1977 dieron el empuje necesario a las transformaciones que condujeron a una enseñanza de calidad. La Ley General de Educación sufrió reformas y contrarreformas a lo largo de las dos décadas de vigencia. Esta ley precursora de modelos democráticos de enseñanza, representa el mejor proyecto educativo de la España contemporánea. La consideración de la educación como tarea permanente se recogía en el articulado de la ley, a la vez constituyó uno de los principios inspiradores de la citada ley (Puelles, 2014:438).

\section{Una intensa política educativa en un escenario cambiante}

Las Escuelas de Magisterio han gozado de un protagonismo ineludible a través en la educación contemporánea. Aunque no mostraron una actitud reivindicativa y fueron siempre dóciles frente a los mandatos oficiales, destacaron por el sólido prestigio científico-académico de muchos profesionales. A pesar de su dinamismo vital no fueron lo suficientemente respetadas por los gobiernos de turno, más bien manejadas a su antojo. Dichas Escuelas experimentaron un salto cualitativo a partir de la Ley General de Educación, pero parece que las señas de identidad del magisterio no terminaron de consolidarse y continuaron con los problemas de antaño, tales como infradotación, precariedades materiales, plantillas insuficientes, inestabilidad, etc. (González, 2013). No se les identificaba como centros específicos de formación y hubo confrontación con el discurso interuniversitario. Si bien, el título de maestro tenía categoría universitaria (diplomado) las instituciones tuvieron dificultades para integrarse en la estructura universitaria. Tanto desde los propios centros normalistas como desde la universidad hubo ciertas resistencias, ya que observaban las distancias que los separaban. A ello añadir que no se estimaban como estudios relevantes ni tenían una consideración académico profesional. Con la Ley de Reforma Universitaria su realidad se complicó aún más. No obstante, la formación inicial de maestros y maestras ha sido producto de la evolución política. El modelo cultural evolucionó, mejoró la formación inicial de los docentes y se transformaron en profesionales cualificados, quedando atrás la práctica "artesana". Los cambios sociales y mejoras económicas facilitaron el acceso de los sectores populares a los estudios universitarios. Esa diversificación generó una mezcla social en las instituciones educativas. Las expectativas profesionales y el ascenso social influyeron en las formas profesionales y culturales, en cuanto a su promoción y acceso a la vida profesional. El perfil académico, el cambio de estatus, la renovación de las prácticas de enseñanza junto las nuevas demandas sociales han influido en las transformaciones de la educación. Con el Plan de Estudios de 1971 se aplicaron otras estrategias pedagógicas y fueron quedando atrás las prácticas desfasadas. La formación profesional del 
alumnado aspirante al magisterio implicaba una cualificación pedagógica y científica en un periodo de tres años. Sin embargo, en este proceso se dedicaron más a atender deficiencias formativas del estudiantado, priorizando su carácter culturalista frente al profesional, relegando las materias pedagógicas y las prácticas de enseñanza (San Román, 2010).

El pertinaz olvido del profesorado en las reformas educativas ha provocado que la aplicación de las mismas no sea efectiva y así sucedió con la Ley General de Educación. No obstante, la reforma educativa propulsada por la LGE construyó un modelo de docente, que influyó en la concepción de la educación, en sus valores y creencias. La Dirección General de Educación Básica desde los inicios de la transición adaptó los programas escolares a la nueva realidad española. Así en 1976 publicó la normativa e introdujo modificaciones de carácter ideológico y psicopedagógico en los contenidos curriculares" (normativa BOE). Se renovaron los enfoques y las pautas metodológicas, al tiempo que se le dieron instrucciones al profesorado para que fomentaran los valores democráticos con el alumnado. En este contexto, el ideal democrático de educación y la defensa de la enseñanza pública ganó fuerza en la época de la transición. Las Escuelas de Verano con planteamientos innovadores, con amplio colectivo de participantes ilusionados, política y éticamente comprometidos, con movilizaciones y asambleas, para aprobar documentos como la declaración por una nueva escuela pública... Fue una época en que la visión social y política de la escuela era clara y fuerte. Donde, además, era evidente la capacidad de la educación para construir la sociedad democrática. En estos años hubo diversas regulaciones conocidas como Programas Renovados. El Real Decreto 3087/1982 de 12 de noviembre (BOE, 22-XI) completó la renovación de los programas educativos de Ciencias Sociales, Lengua Castellana, Ciencias de la Naturaleza y Tecnología, Idiomas, Religión o Ética, Educación Física y Educación Artística, fijando los objetivos y enseñanzas mínimas. Las metodologías, la promoción del alumnado, la asignación del profesorado por especialidad y la figura del profesor tutor eran las novedades destacadas (López, 2001: 204). Los Programas Renovados estructuraban el diseño curricular en ciclos: ciclo inicial, ciclo medio y ciclo superior. Los ciclos ofrecían mayor unidad al proceso educativo, constituían una forma de planificación y reorganización de los contenidos. El diseño curricular venía prescrito desde las instancias superiores y los docentes tenían que aplicarlo a la realidad del aula. De manera que el papel de las maestras y maestros se reducía a la adaptación. De ahí la escasa colaboración en unos programas en los que no habían participado; por tal motivo había disfunciones con las Nuevas Orientaciones. La falta de información, asesoramiento, de innovaciones metodológicas, condujo a la escasa colaboración de las maestras. Pero se implicaron más que los maestros a pesar de sus responsabilidades en la vida privada (López, 2001: 204-212).

Si bien las leyes no cambian la mentalidad, hubo algunas modificaciones curriculares e innovaciones que contribuyeron a transformar la educación. El panorama del magisterio mejoró como consecuencia de los cambios legislativos, incluso los salarios de los maestros crecieron. No obstante, perduraron los roles sexistas y los valores tradicionales en un contexto no exento de problemática. También comenzaba a despuntar la conciencia crítica y la renovación cualitativa de 
la enseñanza y se produjo una apertura a la recepción de las corrientes internacionales; de modo que se introdujeron innovaciones pedagógicas y surgieron movimientos críticos entre el profesorado. Sin embargo, a la magnitud de la reforma emprendida le faltó la correspondencia de los profesionales que tenían que aplicar la normativa y la asignación económica para su puesta en práctica. La deficiente formación pedagógica de un importante sector del magisterio en ejercicio, con sus inercias y rémoras, frenó el proceso. No fue fácil cambiar las rutinas pedagógicas y los esquemas de pensamiento de un profesorado ideologizado por el nacional catolicismo. Los cambios educativos pueden ser prescritos y legislados, pero para que sean efectivos deben adaptarse a la cultura escolar existente y rediseñarse en los contextos educativos (Bolívar, 2013:64). Toda vez que "Las presiones y apoyos de la política educativa desde arriba y las energías de abajo se necesitan mutuamente" para poder desarrollar la propia cultura innovadora, incidiendo en la estructura organizativa, al rediseñar en los contextos laborales para potenciar la toma de decisiones a nivel de cada escuela (Bolivar, 2013:79). El sistema educativo siempre ha situado la formación docente, en el contexto de un discurso ambivalente. Por un lado, la retórica histórica de la importancia de esta formación y, por otro, la precaria situación académica y escasa consideración social. Históricamente, se ha considerado una semiprofesión, pero se requería una serie de conocimientos objetivos prefijados y un conocimiento profesional de carácter pedagógico. Modernizar la educación implicaba necesariamente modernizar al profesorado y sus estructuras formativas. Para ello se afrontó la mejora de la formación inicial y la formación permanente del profesorado (Bolívar, 2013) dado que "la formación del profesorado juega un papel decisivo" (González-Gil y Martín Pastor, 2014,18).

En un periodo de cambios legislativos y de efervescencia social y cultural, la normativa experimentó notables modificaciones. En ninguna época el campo de la educación ha subsistido a los intentos de modificación, a reformas de todo tipo, ni a la persistente crítica desde distintos sectores (Bolívar, 2006). Los problemas educativos básicos se fueron solucionando y al menos se minimizó algo la desigualdad, se controló la presencia de la Iglesia católica y de forma paulatina la descentralización de la gestión educativa. Las señas de identidad del cambio y modernización del ámbito educativo originaron unas generaciones de altos niveles educativos, tanto a nivel cuantitativo como cualitativo. La escolarización se extendió e incluyó a todos en la escuela, aunque no logró la equidad y mostró nuevas formas de segmentación y diferenciación social.

\section{Imaginando la igualdad de género}

Las contradicciones en la igualdad de género presentes en la Ley General de Educación de 1970, que no especificaba las medidas a aplicar, hicieron difícil las prácticas equitativas. La ley tampoco prescindió de todos los conocimientos específicos para cada sexo. Estos siguieron impartiéndose durante algunos años y desaparecieron debido al movimiento de transformación de las 
aulas segregadas en mixtas (Bonal, 2003:79). Un rasgo diferenciador fue el proceso de feminización educativa, la implantación de la coeducación y de un currículo único, aunque en realidad se produjo el establecimiento del modelo masculino suprimiendo las materias específicas para las alumnas, hecho que no solucionó las ancestrales discriminaciones de género (Ballarín, 2001:136-138).

La pretendida igualdad significaba primacía masculina así como adaptarse a intereses y representaciones sociales del modelo masculino (Ballarín, 2004:37). Sin embargo, se pusieron las bases que hicieron posible el reconocimiento del derecho de las mujeres a un modelo de enseñanza en iguales condiciones que los hombres. A partir del plan de estudios de 1971 la feminización de los profesionales de la enseñanza primaria ha sido progresiva. Con excepción de las primeras promociones de egresados de este plan de estudios asistimos a una continuada feminización con la presencia mayoritaria de mujeres en los primeros niveles educativos (San Román, 2010). Es decir, detectamos la feminización del profesorado en la enseñanza infantil y primaria, en la que las mujeres representan en torno al 60-70\% (Albertín y Zufiaurre, 2006; El Sistema Educativo Español, 2009: 205).

En España las maestras, igual que sucedía en otras partes del orbe, desempeñaron un papel decisivo en la formación de las nuevas generaciones, contribuyendo a elevar el nivel cultural de la población, pero también en el proceso de socialización y en la transformación hacia valores democráticos. Las prácticas educativas de las mujeres han transformado y enriquecido la educación. No se trata de un fenómeno nuevo, porque ellas siempre han sido educadoras (García, Calvo y Susinos, 2008: 29). Aunque la tradición y la cultura androcéntricas (que, pese a la evolución, aún siguen fuertemente arraigadas en la sociedad actual) han ignorado esta realidad, el valor de la práctica pedagógica femenina está presente a lo largo de la historia de la educación. La visión androcéntrica ha ignorado el papel desarrollado por las mujeres y las ha arrinconado en su rol sexuado.

La «masculinización del pensamiento» ha incidido en la construcción de las identidades, es decir, de los modelos concretos de masculinidad y feminidad. Era necesario revisar los viejos problemas para afrontar los nuevos desde otras perspectivas de análisis alternativas, que partieran del principio básico de que se vivía en una sociedad sexuada, donde se aceptara la diferencia y la igualdad sexual. El currículo escolar se ha conformado bajo los parámetros de un modelo androcéntrico del conocimiento; resulta imprescindible la inclusión de los saberes femeninos para que lograr la transformación.

La incorporación de la autoridad del saber y de la experiencia de las mujeres en el currículo escolar permite crear una cultura científica que contribuye a la construcción de nuevas identidades de feminidad y masculinidad. También permite mostrar al alumnado valores, códigos y sentimientos distintos de los que han sido atribuidos a cada uno de los sexos y que la actuación humana es siempre sexuada, es decir, con identidad de género. Además de aprender a valorar sin discriminar las aportaciones y las actuaciones de las mujeres y de los hombres, tener una visión más adecuada y realista del mundo. Considerar estos principios necesarios en la práctica educativa garantiza la constitución de una escuela coeducativa y la consecución de una educación científica no discriminatoria, no sexista, marcada con perspectiva de género (Simón, 2010). Aún en la actualidad 
es necesario modificar la práctica educativa y los materiales curriculares como las actitudes e incorporar el enfoque de género (Simón, 2010).

Los saberes de las mujeres quedaron en los márgenes de lo académico, la LGE suprimía las materias específicas para ellas rompiendo con la domesticidad. Se unificaban los espacios, las aulas, los programas, el profesorado pero la cultura académica las seguía olvidando. Las alumnas tenían que demostrar su solvencia científica e intelectual, demostrar con éxito sus aptitudes y cualidades, su valía para acceder al magisterio.

Una carrera de tradición femenina que no escapaba a las desigualdades de género y que bajo el principio de igualdad mantenía las desigualdades (García, Calvo y Susinos, 2008:29). Los roles, la división sexual del trabajo, el lenguaje, las actitudes, los materiales curriculares, en fin toda la cultura académica las ha ignorado e invisibilizado. En la escuela se educaba a las niñas siguiendo el currículum de los niños y a las maestras se les formaba con el programa genérico empleado para los maestros (Subirats, 2010:144). Los cambios de mentalidad han sido lentos y han llegado a golpe de decretos. El acceso masivo de profesoras y alumnas a partir de 1980 provocó un cambio, conscientes de modificar las formas y transformar la educación empleando otras pautas no sexistas marcadas por una auténtica coeducación. En esta década alcanzaron el 50\% del alumnado de bachillerato y una década más tarde representaban el 50\% en los estudios universitarios (Flecha García, 2014:43). Se reflejó la evolución en la trayectoria de la educación de las mujeres y se inició una etapa acorde con los tiempos, en sintonía con los principios y las leyes democráticas (García, Calvo y Susinos, 2008:33). A pesar de la reproducción de los estereotipos de género tanto en los discursos como en la socialización, las mujeres han ido ocupando espacios educativos y profesionales, superando ancestrales interpretaciones que atribuían su rendimiento académico a "su constancia y docilidad más que a su inteligencia" (Flecha García, 2014: 56).

\section{El magisterio y los roles de género}

La unificación del currículum establecido en la normativa (LGE, 1970) no implicó igual formación e idéntica educación. Tampoco surtió efecto en la transformación de la mentalidad de las maestras y de los maestros, ni en las familias. Las formas arcaicas de enseñanza y los viejos estilos docentes empezaron a ser superados, pero buena parte de la práctica escolar siguió bajo la rutina y el rigor disciplinario. Una escuela vigilada por los inspectores e inspectoras de enseñanzas, guardianes de la educación.

Al colectivo modelado con las consignas del régimen autoritario le costó superar los anclajes y adaptarse a las nuevas formas. Los gestos y la retórica que formaban parte del ritualismo de la escuela del régimen se mantuvieron en la etapa de la transición. La rigidez del pensamiento en un proceso lento fue flexibilizando maneras, actuaciones y pensamiento. El rol 
de las maestras se confundía con el rol femenino conservador, porque la educación era un espacio feminizado vinculado al cuidado y atención de la infancia.

Las maestras describían la realidad educativa y social con bastantes elementos comunes, pero con poca incidencia política. La sociedad presenta y verbaliza el discurso sobre las maestras, a modo de eruditas y letradas, que además lo fueron en muchos pueblos españoles aún afectos a la sombría ignorancia. Los modelos de maestras que la gente acuña y normaliza no siempre tienen que ver con el perfil que diseña la administración y la política educativa, aunque la sociedad perpetúa las formas y expectativas de cómo debían ser sus maestras. El protagonismo de las maestras ha marcado sus señas de identidad. Se les identificaba como personas expertas, cultas, con un amplio bagaje de conocimientos, que abarcaban todos los dominios del saber, con una personalidad asociada a una serie de valores éticos.

El género como toda construcción histórica y social se modifica en el transcurso del tiempo. En la conformación del género influyen también las interpretaciones que hacen las instituciones de lo que se considera deberían ser los hombres y las mujeres. Las características de la masculinidad hegemónica promovidas por las instituciones educativas, así como su relación con el proyecto educativo nacional, han estructurado ese tipo de masculinidad ideal. El alumnado fue apropiándose de los discursos y de las prácticas relacionadas con esa construcción. El modelo hegemónico estaba integrado por características que daban respuesta al problema de legitimidad del patriarcado. Además, no todas son valoradas de la misma forma por los grupos sociales, a pesar de que se comparta el mismo espacio social y la época histórica, dando lugar a la aparición de variaciones en el modelo (López Hernández, 2014).

Las instituciones han jugado un papel destacado en la conformación del género y en la proyección de los cambios que tal construcción ha experimentado a lo largo del tiempo. Mediante leyes, normativas, modelos educativos de la Sección Femenina, el régimen franquista impulsó un arcaico arquetipo femenino recatado y sumiso, que expulsaba a las mujeres de toda actividad en el ámbito público, siendo el hogar y la familia los únicos espacios autorizados. Estableció por ley un orden de género de dominio masculino que reguló la dependencia obligada de las mujeres.

Convertidas en seres subalternos, sin derechos, relegadas a la domesticidad forzada del hogar, las mujeres fueron obligadas a permanecer bajo la permanente tutela masculina, sin identidad propia. Los derechos políticos y las conquistas sociales que alcanzaron en la Segunda República, fueron denigrados y rechazados sistemáticamente. Las mujeres ya no tenían lugar en la esfera pública, en el trabajo remunerado, en la política ni en la cultura, excepto en determinadas profesiones relacionadas con los cuidados y atención a la familia, entre ellas se situaba el magisterio (Toboso, 2009: 213-216).

La Constitución de 1978 en su artículo 14 (Título I. De los derechos y deberes fundamentales. Capítulo segundo. Derechos y libertades) recogía la igualdad de sexos, al expresar que "los españoles son iguales ante la ley sin que pueda prevalecer discriminación alguna por razón de nacimiento, raza, sexo, religión, opinión o cualquier otra condición o circunstancia personal o social". La igualdad se convirtió en un mandato constitucional, pero la realidad cotidiana era bien 
distinta. La discriminación era una cuestión naturalizada. En las sucesivas reformas legales se incluyó la igualdad, pero este principio se vulneraba por las creencias, rémoras y prejuicios sociales (Toboso, 2009:217).

El ordenamiento jurídico no resolvía la desigualdad y discriminación, después de décadas de fomentar una educación sexista. La mentalidad de la sociedad aferrada a usos y costumbres fue poco receptiva a modificar esquemas de pensamiento y conductas. Los grupos feministas se movilizaron, pero las maestras, en general, no estaban muy concientizadas. Fueron años de manifestaciones y las mujeres hicieron oír sus voces.

Sin embargo, solo un reducido grupo de maestras participó y se significó, el grueso del colectivo permaneció ajeno. Su conciencia crítica estaba lejos de su reconocimiento como mujeres y de sus derechos como tales, más bien eran reproductoras del orden. Sin embargo se implicaron a nivel profesional y fueron receptivas a los nuevos saberes, a innovaciones didácticas y metodológicas. En estas décadas persistía la socialización diferenciada por género a pesar de que el currículum se había unificado y las enseñanzas pasaron a ser mixtas. Estos sesgos de género incidían en el proyecto laboral y vital de las/ los jóvenes aspirantes al magisterio. También el comportamiento de los egresados y egresadas ha puesto de manifiesto que las opciones académicas y profesionales estaban condicionadas por los convencionalismos y creencias sociales, de manera que conducían a una toma decisiones sesgada por razón de género.

\section{Conclusiones}

En todos los tiempos y en todas las culturas tanto los maestros como las maestras han desarrollado un papel crucial. Sin embargo, socialmente, el personal docente no ha estado suficientemente reconocido y las señas de identidad no han terminado de consolidarse. La implantación de las leyes para las reformas educativas no ha marchado paralela a las culturas profesionales de las distintas generaciones de docentes. Una radiografía de la situación deja entrever que no ha existido una política firme y sostenida de formación inicial y de formación continua del profesorado y que en su periodo de formación no han aprendido a transmitir los conocimientos. Tampoco la formación continua y actualización organizada a través de cursos y seminarios ha resuelto las lagunas de formación y exigencias de la profesión docente. Aunque haya habido intentos importantes se han ignorado las identidades, creencias y prácticas profesionales, hecho que condujo a los desencuentros con las políticas educativas. La divergencia entre la teoría y la práctica ha marcado mayores distancias, cuando debían formar una unidad indisoluble.

A pesar de la presencia de los principios de igualdad en la Ley General de Educación tampoco la formación inicial incorporó la perspectiva de género y la experiencia femenina. El 
recorrido educativo muestra un itinerario sexista marcado por las rémoras culturales conservadoras. Aunque la transformación pacífica del estado político de la dictadura en monarquía constitucional implicó la reformulación de los principios igualitarios no se generalizaron. Las contradicciones en la construcción del modelo educativo igualitario persistía en la conceptualización y práctica educativa afianzada en la diferencia de roles. No obstante, la evolución de la normativa, en el marco democrático, ha posibilitado cambios de comportamiento y ha favorecido la participación del colectivo docente dinamizando la educación. El proceso de modernización educativa ha abierto otros cauces junto a la extensión de la cultura y la aplicación de políticas de igualdad.

\section{BIBLIOGRAFÍA}

- Albertín Lasaosa, Ana y Zufiaurre Goikoetxea, Benjamín (2006): La educación infantil como tarea de maestras: claves de formación y contexto de desarrollo profesional. Barcelona, Octaedro.

- Alonso Hinojal, Isidoro (1991): "Una esperanza ilusoria: la elevación del prestigio del maestro". En: VV.AA. (1991): Sociedad, cultura y educación. Madrid, CIDE/UCM, pp. 355-365.

- Ballarín Domingo, Pilar (2004): "Género y políticas educativas, XXI”. En: Revista de Educación, $\mathrm{n}^{\mathrm{o}}$. 6, $\mathrm{pp}$. 35-42, [en línea] Disponible en http://rabida.uhu.es/dspace/bitstream/handle/10272/1937/b15152844.pdf?sequence=1 [02/01/2016].

- Ballarín Domingo, Pilar (2001): La educación de las mujeres en la España contemporánea. Madrid, Síntesis.

- Blat Gimeno, José (1977): “La crisis del sistema educativo. El derecho a la educación”. En: Revista Escuela Española, no. 2376, pp. 21-22.

- Bolívar, Antonio (2013): "La Lógica del Compromiso del Profesorado y la Responsabilidad de la Escuela. Una Nueva Mirada Escuela”. En: REICE: Revista Electrónica Iberoamericana sobre Calidad, Eficacia y Cambio en Educación, vol. 11, no. 2, pp. 60-86, [en línea] Disponible en: https://ialnet.unirioja.es/servlet/articulo?codigo $=4453235$ [02/01/2016].

- Bolívar, Antonio (2006): "La formación inicial del profesorado y las instituciones de formación". En: José Manuel Escudero y Alberto Luis Gómez (eds.): La formación del profesorado y la mejora de la educación. Barcelona, Octaedro, pp. 123-154.

- Bonal, Javier (2003): “Una evaluación de la equidad del sistema educativo español”. En: Revista de educación, $\mathrm{n}^{\circ} .330$, pp. 59-82.

- Diego Pérez, Carmen (2013): “La con-formación de la profesión de maestro en Educación Infantil”. En: Tabanque Revista Pedagógica, $\mathrm{n}^{\circ}$. 26, pp. 55-71.

- MEC - Ministerio de la Educación, Cultura y Deporte (2009): El sistema educativo español (2009). Vol.1. Madrid: Secretaría General Técnica. Subdirección General de Documentación y Publicaciones.

- Esteve, José Manuel (2003): La tercera revolución educativa. La educación en la sociedad del conocimiento. Barcelona, Paidós.

- Flecha García, Consuelo (2014): "Desequilibrios de género en educación en la España Contemporánea: causas, indicadores y consecuencias". En: Áreas: Revista internacional de ciencias sociales, $\mathrm{n}^{\mathrm{o}}$. 33, pp. 49-60, [en línea] Disponible en: https://dialnet.unirioja.es/servlet/articulo?codigo $=4963202$ [02/01/2016]. 
- González-Gil, Francisca y Martín Pastor, Ma Elena (2014): "Educación para todos: formación docente, género y atención a la diversidad". En: Cuestiones de género: de la igualdad y la diferencia, $\mathrm{n}^{\circ} . \quad$ 9, $\mathrm{p}$. 11-28, [en línea] Disponible en: http://revpubli.unileon.es/ojs/index.php/cuestionesdegenero/article/view/1151/1018 [02/01/2016].

- González Pérez, Teresa (2010): “La transformation de l'education espagnole á la fin du franquisme. La loi générale de l'éducation et la formation d'instituters". En: History of Education Children's Literature, vol. 1, nº . 5, pp. 337-351.

- González Pérez, Teresa (2013): "La formación de maestros durante la transición y la restauración democrática (1976-1986)". En: Revista interuniversitaria de formación del profesorado, nº. 76, pp. 2943.

- Hernández Beltrán, Juan Carlos (2008): "Política y educación en la transición democrática española". En: Foro de Educación, no. 10, pp. 53-93.

- López Hernández, M $M^{a}$ Teresa (2014): "La Formación de las Trabajadoras: una reivindicación sindical (1970-1975)”. En: Cuestiones de género: de la igualdad y la diferencia, nº. 9, pp. 115-133, [en línea] Disponible en: http://revpubli.unileon.es/ojs/index.php/cuestionesdegenero/article/view/1170/1023 [02/01/2016].

- López Hernández, Ma Teresa (2009): "Participación y representación sindical femenina en Comisiones Obreras (1970-1982)". En: Cuestiones de género: de la igualdad y la diferencia, $\mathrm{n}^{\circ}$. 4, pp. 121-146, [en línea] Disponible en: http://revpubli.unileon.es/ojs/index.php/cuestionesdegenero/article/view/3809/2685 [02/01/2016].

- López Martín, Ramón (2001): La escuela por dentro. Perspectiva de la cultura escolar en la España del siglo $X X$. Valencia, Universidad de Valencia.

- Puelles Benítez, Manuel (2011): "De la cátedra de bachillerato al profesorado de educación secundaria”. En: Participación educativa, $n^{\circ}$. extraordinario, pp. 8-28.

. (2009) (coord.): Profesión y vocación docente. Presente y futuro. Madrid, Ed. Biblioteca Nueva. (2014): Ideología y educación en la España contemporánea. Madrid: Tecnos.

- Puelles Benítez, Manuel (2004): Elementos de política de la educación. Madrid, UNED.

- Rodríguez Tapia, R. (2008): "La educación en la transición política Española: Biografía de una traición”. En: Foro de Educación, nº. 10, pp. 93-110.

- San Román Gago, Sonsoles (2010): "La feminización de la profesión: identidad de género de las maestras". En: Revista de la Asociación de Sociología de la Educación, vol. 3, no . 3, pp. 376-387, [en línea] Disponible en: https://dialnet.unirioja.es/servlet/articulo?codigo=3655776 [02/01/2016].

- Simón, Ma Elena (2010): La igualdad también se aprende. Cuestión de educación. Madrid, Narcea.

- Subirats, Marina (2010): “¿Coeducación o escuela segregada? Un viejo y persistente debate”. En: Revista de la Asociación de Sociología de la Educación, vol. 1, nº. 3, pp. 143-158.

- Toboso, Pilar (2009): "Las mujeres en el siglo XXI: igualdad jurídica y discriminación cotidiana". En Pilar Pérez Cantó: De la Democracia ateniense a la Democracia paritaria. Barcelona, Icaria Editorial, pp. 209-228.

- Torres, Jurjo (2011): La justicia curricular. El caballo de Troya de la cultura escolar. Madrid, Morata.

- Torres, Jurjo (1991): "La reforma educativa y la psicologización de los problemas sociales". En VV.AA. En: Sociedad, cultura y educación, Madrid, CIDE/UCM, pp. 481-503.

- Viñao Frago, Antonio (2011): "Del bachillerato de elite a la educación secundaria para todos (España, siglo XX)". En: Guillermo Vicente y Guerrero (coor.): Historia de la Enseñanza Media en Aragón. Zaragoza, Institución "Fernando el Católico" (CSIC), pp. 449-472. 